\title{
openheart Living with heart failure: perspectives of ethnic minority families
}

\author{
Mahdi Shamali (D) , ${ }^{1}$ Birte Østergaard, ${ }^{1}$ Hanne Konradsen ${ }^{2,3}$
}

To cite: Shamali M, Østergaard B, Konradsen $\mathrm{H}$. Living with heart failure: perspectives of ethnic minority families. Open Heart 2020;7:e001289. doi:10.1136/ openhrt-2020-001289

Received 17 March 2020 Revised 24 April 2020 Accepted 6 May 2020
Check for updates

(c) Author(s) (or their employer(s)) 2020. Re-use permitted under CC BY-NC. No commercial re-use. See rights and permissions. Published by BMJ.

${ }^{1}$ Department of Clinical Research, University of Southern Denmark, Odense, Denmark ${ }^{2}$ Department of

Gastroenterology, Herlev and Gentofte University Hospital, University of Copenhagen, Copenhagen, Denmark ${ }^{3} \mathrm{NVS}$, Karolinska Institute, Stockholm, Sweden

Correspondence to Mr Mahdi Shamali; gezaltoshmal@yahoo.com

\section{ABSTRACT \\ Background The family perspective on heart failure (HF) has an important role in patients' self-care patterns, adjustment to the disease and quality of life. Little is known about families' experiences of living with HF, particularly in ethnic minority families. This study describes the experiences of Iranian families living with HF as an ethnic minority family in Denmark.}

Methods In this descriptive qualitative study, we conducted eight face-to-face joint family interviews of Iranian patients with $\mathrm{HF}$ and their family members living in Denmark. We used content analysis with an inductive approach for data analysis.

Results We identified three categories: family daily life, process of independence and family relationships. Families were faced with physical restrictions, emotional distress and social limitations in their daily lives that threatened the patients' independence. Different strategies were used to promote independence. One strategy was normalisation and avoiding the sick role; another strategy was accepting and adjusting themselves to challenges and limitations. The independence process itself had an impact on family relationships. Adjusting well to the new situation strengthened the relationship, while having problems in adjustment strained the relationship within the family. Conclusions This study highlights the process of independence as perceived by families living with HF. It is crucial to both families and healthcare professionals to maintain a balance between providing adequate support and ensuring independence when dealing with patients with HF. Understanding patients' stories and their needs seems to be helpful in gaining this balance.

\section{INTRODUCTION}

Heart disease mortality has decreased over the past few decades in Western countries, including Denmark, even though it remains the most frequent cause of death, morbidity and economic burden for healthcare systems throughout the world. ${ }^{1}$ Among heart diseases, heart failure (HF) has become an epidemic in Europe and worldwide, causing increased healthcare expenditures and rehospitalisations. $^{2}$

The diagnosis of HF influences all aspects of family life and brings multiple challenges to the lives of both patients and their families. ${ }^{3}{ }^{4} \mathrm{HF}$ is a chronic illness and often requires lifestyle changes due to a restricted

\section{Key questions}

What is already known about this subject?

- Heart failure (HF) influences all aspects of family life and brings multiple challenges to the lives of both patients and their families. Most previous research on HF is based on quantitative measurements and sparse qualitative studies that considered patient or partner separately; however, relatively little is known about families' experiences of living with HF particularly in ethnic minority families.

What does this study add?

- This study highlights the process of independence as perceived by families living with HF. Our findings also confirm that interpersonal relationships within the family are an important factor in managing HF.

How might this impact on clinical practice?

- It is important to acknowledge and address the fear of dependence and denial of illness when providing support for patients with HF. Understanding patients' stories and their needs seems to help maintain a balance between providing adequate support and ensuring independence in this endeavour.

life with increased impotence and dependency. ${ }^{5}$ Both patients and families are affected by a patient's health status. Among HF families, couples' adaptation and adjustment to the illness, sexual concerns, changes in daily life, overprotective behaviour and partner control, and shifting of domestic roles within the partner relationship are important issues. ${ }^{67}$ Families often are engaged in patient care in the treatment process of HF, mostly by providing different supporting roles, such as accompanying the patient to healthcare appointments, support for daily tasks, giving emotional support and providing care. ${ }^{8}$ The family perspective of the disease plays an important role in patients' self-care patterns, adjustment to the disease and quality of life. ${ }^{89}$ Therefore, it is essential to understand family experiences of living with HF, not least in ethnic minority groups.

Knowledge of a person's culture, experiences and social environment is crucial to the management of a person's illness. In Iran, for 
instance, it is common to conceal the true diagnosis of acute and chronic diseases from a patient because families are afraid of the loss of hope in patients that could lead to shortening their life. Moreover, some patients with heart disease in Iran view their illness as divinely determined and avoid lifestyle modification. They also consider diet food as being unsocial and isolates them from their social network. ${ }^{10}$ Another example is young Muslim women living with asthma in Denmark. They used praying as an alternative to medicine for controlling their symptoms. ${ }^{11}$ In China, ethnic minority patients with HF used less confrontation coping and more avoidance and acceptance resignation coping strategies. ${ }^{12}$

A patient's attitudes and beliefs regarding health and disease are rooted in family and social values within an ethnocultural background. ${ }^{13}$ Moreover, family structure, function and roles are influenced by culture and world views. ${ }^{14}$ The strategies immigrant families use to cope with the challenges of heart disease vary by ethnicity and length of migration. ${ }^{15}$ Well-understood ethnocultural communication between healthcare workers and patients may improve patients' adaptation to illness. ${ }^{13}$ Insufficient knowledge of cultural differences in patients with heart disease can lead to differential treatment and referral patterns. ${ }^{16}$ Qualitative systematic reviews recommended further studies to explore the experiences of living with HF among people in ethnic minority groups. ${ }^{17} 18$

Most previous research on HF is based on quantitative measurement and sparse qualitative studies that consider patient or partner separately; however, relatively little is known about families' experiences of living with HF, particularly in ethnic minority families. The approximately 22000 Iranians living in Denmark are the 10th largest immigrant group. ${ }^{19}$ To our knowledge, no study regarding ethnic minority families' experiences of living with HF in Denmark has been reported. Therefore, this study aimed to describe the experiences of Iranian families living with $\mathrm{HF}$ as an ethnic minority family in Denmark.

\section{METHOD}

\section{Study design and participants}

A qualitative descriptive design was planned. We collected data using semistructured, in-depth, joint family interviews of patients with $\mathrm{HF}$ and their family members. This paper followed the Consolidated Criteria for Reporting Qualitative Research guidelines for reporting qualitative research.

Participants were Iranian families living in Denmark who had a family member with HF. Participants were recruited through snowball sampling and networking. ${ }^{20}$ No medical records were available to guide the search for potential participants. Therefore, the first families were found through personal contacts and social media; then these families were asked to facilitate contact with other families. The inclusion criteria were being a patient who had a confirmed diagnosis of HF and a family member who had the experience of living with the patient, had come from Iran and lives in Denmark, speaks Persian (Farsi) and has given verbal consent to participate in the study.

\section{Ethical consideration}

All participants were briefed about the study objectives and were informed that their participation is voluntary. Also, all participants were assured of the confidentiality and anonymity of their personal information. As proposed by Voltelen et $a l,{ }^{21}$ ethical considerations were taken into account before (eg, ensuring informants understanding of what participation means), during (eg, being aware of disagreements between interviewees) and after (eg, ensuring the well-being of interviewees) conducting joint interviews.

\section{Data collection}

The face-to-face joint family interviews were conducted in Persian using a semistructured guide at a mutually convenient time and venue, from February to December 2019. Included in the joint family interviews were the patient and one of his/her family members. Eight interviews were conducted in a dedicated private room at participants' homes. Of the eight patients, six were men and two were women. Of the eight family members, seven were spouses (six women and one man) and one daughter. All interviews were digitally recorded, ranging from 35 to $60 \mathrm{~min}$, and conducted by MS, who is proficient in English and Persian. Table 1 shows the self-reported family members' and patients' demographic and clinical characteristics.

A pilot interview was conducted first to test the interview guide for understandability and appropriateness. The interview started with the warm-up question: Can you describe your experiences when you first started having trouble with your heart? followed by an open question: What are your experiences of living with $\mathrm{HF}$ as an Iranian in Denmark? Based on the patient's and his/her family member's answers, the interviewer asked follow-up questions to probe and clarify the experiences of a family living with HF. Examples of follow-up questions were as follows: How does the illness affect the daily life of your family/relationship? Can you describe a situation that illustrates what it is like to live with HF?

\section{Data analysis}

For data analysis, interviews were transcribed verbatim and checked against audio recordings to ensure accuracy. Then, Persian transcriptions were translated into written English so that the team's two coresearchers could discuss and take part in the analytical process.

Content analysis using an inductive approach as proposed by Graneheim $e t a t^{22}$ was performed to guide the data analysis process. To allow for immersion and a sense of the whole, transcripts were read thoroughly multiple times. The text was then imported into the software programme NVivo V.12 (QSR International) to organise and manage the data. This was followed by 
Table 1 Characteristics of patients and family members

\begin{tabular}{|c|c|c|c|c|c|c|c|c|c|}
\hline \multirow[b]{2}{*}{ Characteristics } & & \multicolumn{8}{|l|}{ Family } \\
\hline & & 1 & 2 & 3 & 4 & 5 & 6 & 7 & 8 \\
\hline \multirow[t]{10}{*}{ Patient } & Sex & Male & Male & Male & Male & Male & Female & Female & Male \\
\hline & Age (years) & 58 & 65 & 74 & 76 & 60 & 60 & 65 & 70 \\
\hline & Marital status & Married & Married & Married & Married & Married & Married & Married & Married \\
\hline & Work & Yes & No & No & No & Yes & No & No & No \\
\hline & Duration of HF (months) & 10 & 12 & 24 & 12 & 6 & 5 & 12 & 18 \\
\hline & NYHA classification & I & I & $\|$ & ॥ & $\|$ & $\|$ & $\|$ & $\|$ \\
\hline & Aetiology of HF & $\mathrm{IHD}$ & $\mathrm{IHD}$ & $\mathrm{IHD}$ & $\mathrm{IHD}$ & $\mathrm{IHD}$ & IHD & $\mathrm{IHD}$ & $I H D$ \\
\hline & LVEF \% & 40 & 40 & 40 & 40 & 20 & 40 & 30 & 35 \\
\hline & Comorbidity & $\mathrm{Ml}$ & RA, HTN & $\begin{array}{l}\text { HTN, } \\
\text { hearing loss }\end{array}$ & MI, HTN & Ml & MI, HTN & MI, DM & $\mathrm{Ml}$ \\
\hline & Years living in Denmark & 28 & 29 & 28 & 30 & 30 & 30 & 27 & 30 \\
\hline \multirow[t]{5}{*}{ Family member } & Sex & Female & Female & Female & Female & Female & Male & Female & Female \\
\hline & Age (years) & 53 & 60 & 65 & 68 & 52 & 65 & 35 & 63 \\
\hline & Marital status & Married & Married & Married & Married & Married & Married & Married & Married \\
\hline & Work & Yes & No & Yes & Yes & Yes & No & Yes & Yes \\
\hline & Relation to patient & Spouse & Spouse & Spouse & Spouse & Spouse & Spouse & Daughter & Spouse \\
\hline
\end{tabular}

DM, diabetes mellitus; HF, heart failure; HTN, hypertension; IHD, ischaemic heart disease; LVEF, left ventricle ejection fraction; MI, myocardial infarction; NYHA, New York Heart Association classification of heart failure; RA, rheumatoid arthritis.

extraction of meaning units, which were then condensed, abstracted and labelled with a code. The various codes were grouped into subcategories and categories through a process of comparison based on differences and commonalities. Then, all members of the team reviewed and discussed tentative categories and coding until consensus was achieved.

\section{Rigour}

The model of trustworthiness proposed by Elo $e t a l^{23}$ was pursued to ensure rigour and trustworthiness. In the present study, credibility was enhanced by the data collection method (interviews), performing the first interview with a coresearcher who is an expert in the qualitative field and discussing the findings among the research team. Transferability was strengthened by a clear description of the setting, the sample's characteristics, and the process of data collection and analysis. Findings are illustrated with quotations. Dependability was increased by engaging the two coresearchers of the team in data analysis and discussion of the final categories. Confirmability was strengthened by comparing findings with reported research.

\section{FINDINGS}

Three main categories were identified: family daily life, process of independence and family relationships. Families with HF were constantly confronted with new challenges and limitations in their daily lives. They were shocked by receiving the diagnosis of the disease and searched for social and professional support, trying to understand and to overcome the situation. Families were faced with physical restrictions, emotional distress and social limitation in their daily lives, which threatened the patients' independence. Different strategies were used to promote independence. One strategy was normalisation and avoiding the sick role; another strategy was accepting and adjusting themselves to challenges and limitations by searching for support and modifying family daily tasks. The independency process itself had an impact on the family's relationships. Adjusting well to the new situation strengthened the relationship, while having problems in adjustment strained the relationship within the family. Table 2 shows the overview of the study's findings with the example of codes and condensed meaning units.

\section{Family daily life}

This category illustrates challenges, changes and limitations that Iranian families with HF deal with in everyday life in Denmark, including physical restrictions, emotional distress and social limitations.

\section{Physical restrictions}

Patients experienced that their physical activities had decreased since the diagnosis of HF. There were certain things they used to do but were no longer able to do, so they had to live more calmly.

Patient: 'I feel I should slow done the speed of my train'. (Family 5)

The diminished activities were influenced by symptoms such as tiredness, breathlessness and chest pain during 
Table 2 Overview of the categories and subcategories identified in the study with the example of codes and condensed meaning units

\begin{tabular}{|c|c|c|c|}
\hline $\begin{array}{l}\text { Example of condensed meaning } \\
\text { units }\end{array}$ & Example of codes & Subcategories & Categories \\
\hline $\begin{array}{l}\text { I am not able to do activities that I used to do. } \\
\text { When I do little activities, I become tired and } \\
\text { need rest. }\end{array}$ & $\begin{array}{l}\text { Decreased physical activities } \\
\text { Fatigue and low energy }\end{array}$ & Physical restrictions & Family daily life \\
\hline $\begin{array}{l}\text { I am afraid of being alone. I was worried } \\
\text { what would happen to me. I do not have idea } \\
\text { and motivation for the future like before. }\end{array}$ & $\begin{array}{l}\text { Patient's fear } \\
\text { Anxiety } \\
\text { Hopeless }\end{array}$ & Emotional distress & \\
\hline $\begin{array}{l}\text { I have nobody to help me; you cannot ask for } \\
\text { help at all times. }\end{array}$ & $\begin{array}{l}\text { Patient's fear of losing } \\
\text { independency }\end{array}$ & Fear of becoming dependent & Process of independence \\
\hline $\begin{array}{l}\text { I do not collaborate with heart association } \\
\text { because it gives me a feeling of being ill. I do } \\
\text { not feel that I am ill. }\end{array}$ & $\begin{array}{l}\text { Avoiding sick roles } \\
\text { Normalisation }\end{array}$ & Facing dependency & \\
\hline $\begin{array}{l}\text { The illness made our family closer. She (wife) } \\
\text { started to love me so much. }\end{array}$ & $\begin{array}{l}\text { Good communication } \\
\text { Positive effect of illness on } \\
\text { relationships }\end{array}$ & Strengthened relationship & \\
\hline
\end{tabular}

physical activities. Some experienced low energy and decreased motivation to start new activities. This could give meaning in the light of HF but was also experienced as being related to old age. When decreased physical activities in the patients led to decreased ability to do daily tasks, family members tasks' load increased to compensate and maintain family daily life.

Family member: 'My daily tasks have increased. I used to work 2 hours in our shop, but now work more. I take the children to school and bring them home. I go shopping alone'. (Family 5)

Furthermore, the desire for sexual relationship diminished following $\mathrm{HF}$ as a result of medications. The weak sexual relationship led to decreased family intimacy.

Patient: 'Our sex life has suffered. When sexual intimacy decreases, your relationship becomes cold'. (Family 2)

Patients also complained about the side effects of the medications. Bleeding was a common complication of using anticoagulants. It was very scary for the family members to see patients' nosebleeds. Patients believed that their mood changed because of medications, becoming unstable and irritable, especially in the morning.

\section{Emotional distress}

The shock of receiving the diagnosis and the worry about the unknown future were followed by feelings of anxiety. When patients were alone at home or out visiting friends, families worried about what would happen if the patient had a new heart attack. Some family members called patients regularly to check their health status. Family members also worried more when patients could not do the daily tasks as they used to do. Spouses' worries were understood by the patients and mentioned as natural among couples, but they also got annoyed if their spouses worried too much.

Most patients worried about a new heart attack and death, especially at the beginning of HF. Some patients could not sleep and were afraid of being alone and becoming ill in a place where no one could save them. One patient described:

I have a fear of enclosed spaces. Like when I'm in a room and the door is closed and I cannot open it. I panic. I have got this strong feeling when I had a heart attack. (Family 1)

There was a feeling of hopelessness and a loss of motivation for the future at the beginning of HF; therefore, families saw it as their task to give patients hope and encourage optimism.

Family member: 'He lost hope and believed he couldn't get through this new situation. We tried to speak to him and give him hope.' (Family 8 )

There was an experience of increased irritability, being more impatient and critical of others. It was difficult to be in a busy environment, which triggered a feeling of not being able to concentrate on daily tasks and a desire to be alone. Patients spoke critically of their own and others' past behaviours, even though family members got annoyed when patients talked a lot about the past. 
Social limitation

Family social life changed as a result of HF, and family joint activities were highly affected. Families changed their hobbies and activities so that the patients could also participate. Physical limitations and being impatient and intolerable were the most common reasons for the decrease in joint activities. Children were often left to themselves as a result of fewer joint activities.

Patient: 'I feel that they [the children] are more alone. My children used to tell me about their problems, and I helped them to solve them, now I can't'.

(Family 5)

Physical limitations and emotional distress led to substantial social isolation. For example, patients' worklife changed because they were unable to perform their duties at work. They tried to amuse themselves by working in their gardens at home. Patients also avoided social events because of emotional distress. Sometimes, patients declined to participate in social events, giving the excuse that they were busy or not interested rather than saying they could not participate because of physical limitations or emotional distress. Families often became socially isolated because they did not tell their neighbours and friends about the HF. They believed that it was not necessary to tell others about the disease, consequently, limiting their social contacts.

\section{Process of independence}

This category illustrates the way families dealt with dependence and how they tried to maintain and restore the independence of the patient with HF through different strategies. The process of independence started with the fear of becoming dependent and continued to face the dependency.

\section{Fear of becoming dependent}

It was frustrating for patients to lose control over their lives and worry about the unpredictable future of $\mathrm{HF}$, which limited their choices in daily life. They were afraid of becoming dependent on others, and this gave them a feeling of being caged in by HF.

Patient: 'I'm scared of what will happen to me. What if I have another attack and am immobilised or handicapped. Losing my independence is a big nightmare for me'. (Family 6)

Spouses were worried that patients could become more dependent in the future. They had no idea what to do if patient's condition became worse but tried to stay positive about the future.

\section{Facing dependency}

Patients with HF faced dependence due to deteriorating health but strived to be independent using different strategies. One strategy was normalisation and avoiding the sick role. For example, they tried to hide limitations by stating that they had no problems in their daily lives and relationships, but after they started talking, they mentioned their problems. Patients perceived some level of limitation to be natural due to age and not related to HF. Patients were unwilling to be called a patient because they considered the term patient and illness a disability or limitation. Patients avoided activities that gave the feeling of being sick, such as being a member of a patient association. Moreover, patients refused support from the municipality and tried not to be a burden on the family to show their independence. In one family, normalisation had a life-threating consequence leading to the patient's second heart attack.

Patient: 'One weekend, I had a headache and a feeling of nausea [crying]. My children said: mum, you are not OK! I said: Yes, but it's not serious, I will contact my doctor on Monday. The family wanted to call an ambulance, but I said no. Later, I started to have chest pain and breathlessness. I called my son, and he came and took me to the hospital. That was terrible'. (Family 6)

Another strategy was accepting and adjusting to challenges and limitations. Families talked about adaptation as an aspect that helped them to integrate the restrictions into their lives and did not perceive this new situation as problematic, accordingly being able to manage their daily life successfully.

Family member: 'Well, when we want to go out, we try to find a place he can also come to. We let him rest when he gets tired. We always find a solution'. (Family 4)

Patients believed that adaptation was harder for their family members than for themselves. Families searched for support to facilitate the adjustment process, and other family members and healthcare professionals were the most important sources of support. All families were satisfied with the support from healthcare professionals and felt they received the support they needed. Some families lacked family support because they lived alone. Families said there was no need to ask for support from neighbours or friends. Family members supported patients in daily life challenges and limitations but could not provide enough support when patients had emotional distress, so they also needed support from healthcare professionals.

\section{Family relationships}

This category illustrates the impact of HF on family relationships. Family relationships were influenced by the way families were confronted with dependence as a result of challenges, changes and limitations caused by HF. Adjusting well to the new situation strengthened the relationship, while having problems in adjustment strained the relationship within the family.

\section{Strengthened relationship}

Despite great limitations and distress following HF, some families reported that the disease had brought them 
closer and increased solidarity. These families communicated well with each other and mutually adapted to this new situation following HF. Grandchildren were a good source of solidarity in the family.

Patient: 'Visiting my grandchildren makes me feel good. I enjoy playing with them'. (Family 8 )

Patients always looked forward to seeing their grandchildren. The future of the children and grandchildren was the highest priority in the family. Families tried their best to facilitate a bright future for their children and grandchildren. From the time HF was diagnosed, family members had more contact with the patient, were more available and visited more frequently. Families were engaged in HF management and tried to provide support to ease the process of adjustment, and in some situations, they also tried to adjust along with the patient.

\section{Strained relationship}

Family members experienced that it was difficult to deal with patients' normalisation; being constantly worried about patients resulted in overprotective behaviour.

Family member: 'When we were taking care of him, he said why are you doing this, I'm OK. I force him to go to the check-ups and encourage him to request more check-ups, but he doesn't think it's t necessary. If he needed more check-ups, the doctors would tell him, he says'. (Family 1)

Patients withheld their feelings, emotions and symptoms in order not to cause anxiety in the family, which made them more isolated. Families found it hard to communicate with patients who hid their feelings and distress, making it impossible for them to offer help and support in many situations, which resulted in patients being left on their own. Some families did not talk with patients during their emotional turmoil, trying not to make the situation worse. They tried not to communicate with patients when they were in a bad mood. Examples of arguments were when patients forgot to take medications and family members had to remind them.

\section{DISCUSSION}

To our knowledge, this is the first study that describes the experiences of ethnic minority families living with HF using the joint family interview. Our key findings depict the daily challenges, changes and limitations imposed by $\mathrm{HF}$ on patients and their family members, which led to many physical and social restrictions, with distressing consequences for the affected Iranian families in Denmark. Consistent with our findings, the various physical problems (eg, breathlessness, chest pain, fatigue, decreased sexual function and side effects of medications) and emotional strains (eg, anxiety, fear and anger) were consistently reported in international studies on Eastern and Western patients with HF. ${ }^{24-26}$ Furthermore, changes in daily life and domestic roles, fatigue and anxiety in family members were identified in families with HF. ${ }^{626} 27$ In line with others, we found that HF causes multiple progressive losses, leading to changes in or loss of social and joint activities, jobs and social roles. ${ }^{5}$ These consequences could affect well-being and result in emotional distress and compromise quality of life in patients with $\mathrm{HF}^{71824}$ and their family members. ${ }^{26}$

This study highlights the process of independence. Families with HF faced progressive, inevitable dependence due to deteriorating health and debilitating life. We noted a similar strong fear of becoming dependent on others and a tendency to be independent in studies on patients with different ethnicity and culture. ${ }^{24} 28{ }^{29}$ Independency preserves dignity, self-responsibility and self-control, which are important values in the actions and decisions of daily life. ${ }^{28}{ }^{30}$ In response to the physical, emotional and social effects of HF, patients developed different strategies to diminish the impact on their daily lives and maintain independence. Although some patients and family members in our study tried to pretend that everything was normal and avoided adopting a sick role, others tried to understand and accept these limitations and changes in daily life, accordingly, adjusting themselves to this new situation. A review of qualitative studies by Jeon $e t a l^{17}$ also reported that patients with HF use two common coping strategies, including sharing the illness experience with others and being flexible to changing situations to overcome the limitations imposed by the illness. Sharing experiences of HF with family members strengthen family relationships. Sharing experiences with others can also provide an opportunity to receive social support and overcome social isolation. ${ }^{17}$ In contrast to our findings, a study on Asian patients with HF reported spirituality as a coping strategy that helps patients to deal with this new situation. ${ }^{24}$ A study conducted in Iran also reported that some patients with heart disease consider their illness as divinely determined, which hinders them to change their lifestyle. ${ }^{10}$

Normalisation and avoiding the sick role were often seen in our patients. Similarly, normalisation was reported as a management strategy in the families of young patients with congenital heart disease. ${ }^{31}$ Kaholokula et $a \hat{l}^{2}$ reported illness denial among patients with HF and considered it as a type of passive coping style. Kaholokula et al reported two possible reasons, including fear of HF and lack of knowledge about patients' denial of their illness. In our study, patients who used normalisation and avoided the sick role did not want to talk about their limitations or share experiences with others because they thought it would represent a loss of independence and self-control. In patients with chronic illnesses, it demands time, courage and trust to open up about illnesses and their impact on daily life and to ask for help. The situation can be complicated when patients hide their illness and suffering in order not to disturb those who would be able to help and support them. ${ }^{30}$ Therefore, it is important to acknowledge and address the fear of dependence and denial of illness while providing support for patients with HF. 
Family members were aware of limitations and challenges and tried to help patients who used normalisation to adjust. But patients resisted accepting this new situation. In return, family members were constantly worried about the patients' health; accordingly, they adopted overprotective behaviours. Overprotection refers to overhelping or restricting the patient in performing activities within a partner relationship. ${ }^{6}$ Consistent with the findings of Dalteg et al, ${ }^{6}$ we found an overprotective behaviour from spouses towards patients regarding performance of activities and concerning lifestyle changes. Overprotective behaviours may cause higher levels of anxiety and depression in patients and make them feel frustrated. ${ }^{33}$ However, the patients in our study considered it to be normal behaviour among couples. This might be related to the fact that the patients in our study were mostly men and believed that female spouses care more than male spouses.

In our study, families were satisfied with perceived support from healthcare professionals, but they lacked family support. In contrast, Etemadifar $e t a l^{27}$ conducted a qualitative study of family caregivers' experiences of caring for patients with HF in Iran and reported a lack of both familial and professional support. The reason for the lack of familial support in our study was the unavailability of the family member because the patients lived alone in Denmark. Although family members were available in the study of Etemadifar et al, they did not have enough knowledge to support patients. Unlike our study, previous studies reported inadequate support from healthcare professionals in patients with HF. ${ }^{2432}$ Professional support, in terms of informational and instrumental support, plays an important role in the adjustment process of families with HF. Social support from nurses can enhance family health and family functioning in families with HF, which are important elements in lifestyle modification. ${ }^{34}$ Social support can also enhance patients' ability to self-manage their conditions. ${ }^{24}$ Hence, by gaining insight into families with HF's experiences, nurses and other healthcare professionals can effectively help them to adjust to the new situation. Moreover, the lack of family support in the form of informational support is associated with more psychological distress and poorer quality of life among patients with $\mathrm{HF}^{32}$ Family nursing therapeutic conversations improve perceived professional social support in both patients and their family members with HF. ${ }^{34}$ Therefore, nurses might be a good source of support to reinforce family support in HF, particularly among ethnic minority families.

In our study, a profound impact of HF on family relationships was found. We identified a shift in roles and responsibilities within the family relationship in response to the progressive dependency, which is in line with previous studies. ${ }^{6}{ }^{35}$ Family members modified their daily lives to meet the patients' needs and to compensate for the limited capacity of patients to perform daily tasks, resulting in less time for themselves and limited opportunities to socialise with others. Although family members' daily tasks had increased and their lives were restricted, they did not perceive these as burdensome but as tightening relationships and contributed to a feeling of solidarity. ${ }^{35} 36$ The love and affection of the relationship motivate families to feel responsible for the patients. ${ }^{37}$ Similar to our finding, grandchildren were reported as playing a highly supportive role, possibly because children do not see their grandparent as an ill person, hence offering freedom in the role as a grandparent. ${ }^{38}$ Furthermore, in our study, some patients and family members experienced strained relationships. This might be due to the challenges faced by families in their daily lives because these could be extremely significant and complex, making it difficult for families to adjust properly to the new situations. Sometimes patients were not cooperative in the adjustment process due to normalisation and avoiding the sick role. Consistent with the finding of Dalteg et $a l,{ }^{6}$ family members found it hard to communicate with patients during their emotional turmoil, which resulted in patients being neglected by family members and isolated in the family. Our findings, in line with previous studies, indicate that interpersonal relationships within the family are an important factor in managing $\mathrm{HF}^{37}$

The findings in this study must be considered with some limitations. Most patients were men $(n=6)$, had mild HF (New York Heart Association classifications I and II) and were in relatively stable condition. Most family members were female spouses. Therefore, our findings should be transferred with caution to other types of patients and their family members. Future research considering female patients and male spouses with advanced HF may enrich our knowledge about the experiences of ethnic minority families living with HF. Our findings may reflect a sampling bias as we used snowball sampling; we might have included participants with their peers who share similar characteristics and experiences.

\section{CONCLUSION}

Consistent with previous studies, our finding showed that HF restricted many aspects of the daily life of Iranian families living with HF in Denmark. Moreover, the process of maintaining independence had a strong impact on family relationships, from strengthening the relationships to becoming overprotective spouses or withdrawing from patients, leaving them alone. Participants in our study received satisfactory support from healthcare professionals in Denmark; however, they lacked family support. Maintaining a balance between providing adequate support and ensuring independence is an important element that should be considered by both families and healthcare professionals when dealing with patients with HF. Understanding patients' stories and their needs seems to be helpful to gain this balance.

Acknowledgements The authors thank the families who participated in this study.

Contributors MS performed the interviews, collected the data and drafted the initial manuscript. All authors were involved in the study concept and design, 
data analysis and interpretation of the data; critically revised the manuscript for important intellectual content; and gave their final approval of the version to be published.

Funding This work was funded by the Novo Nordisk Foundation under grant Number NNF170C0027968.

Competing interests None declared.

Patient consent for publication Obtained.

Ethics approval The study has been approved by the University of Southern Denmark, Odense, Denmark (journal number 18/24435). Formal ethical permission was not required according to the Scientific Ethics Committees for the Region of Southern Denmark (number: 20182000-73).

Provenance and peer review Not commissioned; externally peer reviewed.

Data availability statement All data relevant to the study are included in the article or uploaded as supplementary information. All data relevant to the study are included in the article.

Open access This is an open access article distributed in accordance with the Creative Commons Attribution Non Commercial (CC BY-NC 4.0) license, which permits others to distribute, remix, adapt, build upon this work non-commercially, and license their derivative works on different terms, provided the original work is properly cited, appropriate credit is given, any changes made indicated, and the use is non-commercial. See: http://creativecommons.org/licenses/by-nc/4.0/.

ORCID iD

Mahdi Shamali http://orcid.org/0000-0001-7628-0887

\section{REFERENCES}

1 Joensen AM, Joergensen T, Lundbye-Christensen S, et al. Explaining trends in coronary heart disease mortality in different socioeconomic groups in Denmark 1991-2007 using the IMPACTSEC model. PLOS One 2018;13:e0194793.

2 Tripoliti EE, Papadopoulos TG, Karanasiou GS, et al. Heart failure: diagnosis, severity estimation and prediction of adverse events through machine learning techniques. Comput Struct Biotechnol J 2017; 15:26-47.

3 Hagan N, Currey J. Living with heart failure: partner perspectives. Aust Crit Care 2007;20:113-5.

4 Nimmon L, Bates J, Kimel G, et al. Patients with heart failure and their partners with chronic illness: interdependence in multiple dimensions of time. J Multidiscip Healthc 2018;11:175-86.

5 Ryan M, Farrelly M. Living with an unfixable heart: a qualitative study exploring the experience of living with advanced heart failure. Eur $J$ Cardiovasc Nurs 2009;8:223-31.

6 Dalteg T, Benzein E, Fridlund B, et al. Cardiac disease and its consequences on the partner relationship: a systematic review. Eur $J$ Cardiovasc Nurs 2011;10:140-9.

7 Walsh A, Kitko L, Hupcey J. The experiences of younger individuals living with heart failure. J Cardiovasc Nurs 2018;33:E9-16.

8 Voltelen B, Konradsen H, Østergaard B. Family nursing therapeutic conversations: family reorganization processes after diagnosis. Fam Relat 2018;67:600-14.

9 Gallant MP, Spitze G, Grove JG. Chronic illness self-care and the family lives of older adults: a synthetic review across four ethnic groups. J Cross Cult Gerontol 2010;25:21-43.

10 Farahani MA, Mohammadi E, Ahmadi F, et al. Cultural barriers in the education of cardiovascular disease patients in Iran. Int Nurs Rev 2008;55:360-6.

11 Druedahl LC, Yaqub D, Nørgaard LS, et al. Young Muslim women living with asthma in Denmark: a link between religion and selfefficacy. Pharmacy 2018;6:73.

12 Rong X, Peng Y, Yu H, et al. Factors associated with adoption of coping strategies among Chinese patients with heart failure in ethnic minority regions. J Clin Nurs 2018;27:3324-34.

13 Howlett JG, McKelvie RS, Costigan J, et al. The 2010 Canadian cardiovascular Society guidelines for the diagnosis and management of heart failure update: heart failure in ethnic minority populations, heart failure and pregnancy, disease management, and quality improvement/assurance programs. Can J Cardiol 2010;26:185-202.

14 Dunbar SB, Clark PC, Quinn C, et al. Family influences on heart failure self-care and outcomes. J Cardiovasc Nurs 2008;23:258-65.

15 Liu LW, McDaniel SA. Family caregiving for immigrant seniors living with heart disease and stroke: Chinese Canadian perspective. Health Care Women Int 2015;36:1327-45.

16 Ski CF, Thompson DR, Fitzsimons D, et al. Why is ethnicity important in cardiovascular care? Eur J Cardiovasc Nurs 2018;17:294-6.

17 Jeon Y-H, Kraus SG, Jowsey T, et al. The experience of living with chronic heart failure: a narrative review of qualitative studies. BMC Health Serv Res 2010;10:77.

18 Yu DSF, Lee DTF, Kwong ANT, et al. Living with chronic heart failure: a review of qualitative studies of older people. J Adv Nurs 2008;61:474-83.

19 Integrationsministeriet U-o. International Migration Denmark - 2019 2019 [updated 27.11.2019. Available: https://uim.dk/publikationer/ international-migration-denmark-2019

20 Patton MQ. Qualitative research \& evaluation methods: Integrating theory and practice. Fourth. Sage publications, 2015.

21 Voltelen B, Konradsen H, Østergaard B. Ethical considerations when conducting joint interviews with close relatives or family: an integrative review. Scand J Caring Sci 2018;32:515-26.

22 Graneheim UH, Lindgren B-M, Lundman B. Methodological challenges in qualitative content analysis: a discussion paper. Nurse Educ Today 2017;56:29-34.

23 Elo S, Kääriäinen M, Kanste O, et al. Qualitative content analysis: a focus on trustworthiness. Sage Open 2014;4:2158244014522633.

24 Seah ACW, Tan KK, Huang Gan JC, et al. Experiences of patients living with heart failure: a descriptive qualitative study. $J$ Transcult Nurs 2016;27:392-9.

25 Boyd KJ, Murray SA, Kendall M, et al. Living with advanced heart failure: a prospective, community based study of patients and their carers. Eur J Heart Fail 2004;6:585-91.

26 Pattenden JF, Roberts H, Lewin RJP. Living with heart failure; patient and carer perspectives. Eur J Cardiovasc Nurs 2007;6:273-9.

27 Etemadifar S, Bahrami M, Shahriari M, et al. Family caregivers' experiences of caring for patients with heart failure: a descriptive, exploratory qualitative study. J Nurs Res 2015;23:153-61.

28 Falk H, Ekman I, Anderson R, et al. Older patients' experiences of heart failure-an integrative literature review. J Nurs Scholarsh 2013:45:n/a-55.

29 Sundin K, Bruce E, Barremo A-S. Elderly women's experiences of support when living with congestive heart failure. Int J Qual Stud Health Well-being 2010;5:5064.

30 Delmar C, Bøje T, Dylmer D, et al. Independence/dependence--a contradictory relationship? Life with a chronic illness. Scand J Caring Sci 2006;20:261-8.

31 Claessens $\mathrm{P}$, Moons $\mathrm{P}$, de Casterlé $\mathrm{BD}$, et al. What does it mean to live with a congenital heart disease? A qualitative study on the lived experiences of adult patients. Eur J Cardiovasc Nurs 2005;4:3-10.

32 Kaholokula Joseph Keawe'aimoku, Saito E, Mau MK, et al. Pacific Islanders' perspectives on heart failure management. Patient Educ Couns 2008;70:281-91.

33 Joekes K, Maes S, Warrens M. Predicting quality of life and self-management from dyadic support and overprotection after myocardial infarction. Br J Health Psychol 2007;12:473-89.

34 Shamali M, Konradsen H, Stas L, et al. Dyadic effects of perceived social support on family health and family functioning in patients with heart failure and their nearest relatives: using the Actor-Partner interdependence mediation model. PLoS One 2019:14:e0217970.

35 Aldred H, Gott M, Gariballa S. Advanced heart failure: impact on older patients and informal carers. J Adv Nurs 2005;49:116-24.

36 Luttik ML, Blaauwbroek A, Dijker A, et al. Living with heart failure: partner perspectives. J Cardiovasc Nurs 2007;22:131-7.

37 Kim JSR, Risbud R, Gray C, et al. The Dyadic experience of managing heart failure: a qualitative investigation. $J$ Cardiovasc Nurs 2020;35:12-18

38 Welstand J, Carson A, Rutherford P. Living with heart failure: an integrative review. Int J Nurs Stud 2009;46:1374-85. 